\title{
Corrigendum
}

\section{Psychobiological correlates of smoking in patients with erectile dysfunction}

G Corona, E Mannucci, L Petrone, V Ricca, R Mansani, A Cilotti, G Balercia, V Chiarini, R Giommi, G Forti and M Maggi

International Journal of Impotence Research (2005) 17, 553. doi:10.1038/sj.ijir.3901363

Correction to: International Journal of Impotence Research (2005) 17, 527-534. doi:10.1038/sj.ijir.3901351; published online 2 June 2005

Following the publication of this article, the authors identified the following errors:

1. In the author affiliations, the fifth affiliation should read 'Endocrinology Unit, Maggiore-Bellaria Hospital, Bologna, Italy' and not 'Endocrinology Unit, Haggore-Bellaria Hospital, Bologna, Italy.'

2. An Acknowledgements section should have been included.

\section{Acknowledgements}

We thank Angela Magini, Csilla Krausz, Andrology Unit, University of Florence, Marco Bartolini, Radiology Unit, University of Florence, for their helpful clinical collaboration during the course of the study. This study was partially supported by a grant from, Bayer S.p.A, Milano, Italy and by Centro di Ricerca Trasferimento ed Alta Formazione MCIDNENT of the University of Florence. 